\title{
LOS JUROS DE ECLESIASTICOS. PARTICIPACION DE LOS CONVENTOS ANDALUCES EN LA DEUDA PUBLICA CASTELLANA
}

\author{
ANTONIO LUIS LOPEZ MARTINEZ \\ Universidad de Sevilla
}

«... que en adelante se mire el recato y madurez con que otra vez se ha de tratar con la Hacienda Real».

RinCón: Protocolo del Monasterio de Santa María de las Cuevas ${ }^{1 .}$

\section{RESUMEN}

Durante los siglos XVI y XVII en la Iglesia española predominó una mentalidad de carácter marcadamente rentista. Sus inversiones iban dirigidas a la adquisición de propiedades inmobiliarias, para ser cedidas en arrendamiento, 0 a la concesión de créditos, tanto privados (censos consignativos) como públicos (juros). A lo largo del siglo XVI, las instituciones eclesiásticas terminaron por convertirse en las principales acaparadoras de títulos de deuda pública. Los privilegios concedidos por la Corona permitieron a los eclesiásticos situarse en una posición ventajosa a la hora de adquirir nuevos títulos mediante operaciones especulativas que rozaban lo fraudulento. Sin embargo, la quiebra de la monarquía española acabó por afectar también a la Iglesia, situando algunas instituciones en graves dificultades financieras.

\section{ABSTRACT}

A strongly rentier mentality prevailed in the Spanish Catholic church during the XVIth and XVIth centuries. Investments were applied to the acquisition of real estate properties to be rented for long periods of time, or used to grant credits, either private ones (censos consignativos) or public credits (juros). Church institutions finally became during the xVIIth century the main monopolizers of public debt bonds. The advantages granted by the Crown allowed the clergy a propitious position for the acquisition of new bonds by means of speculative operations that were nearly fraudulent. However, the bankruptcy of the Spanish monarchy eventually affected the Church itself, and it placed some institutions in a difficult financial position.

\footnotetext{
1 Citado por Cuartero Huerta (1950), v. 2, p. 194.
} 


\section{INTRODUCCION}

La bibliografia sobre los juros, aunque no copiosa, es lo suficientemente importante como para que su origen, funcionamiento y diversas vicisitudes nos sean bastante bien conocidos ${ }^{2}$. Sin embargo, dicha bibliografia presenta un marcado carácter oficial, ya que se basa, en casi su totalidad, en documentación emanada de la Hacienda Real, habiéndose prestado poca atención, tal vez por el carácter macroeconómico que ha revestido el análisis de los juros, a las fuentes privadas, es decir, la documentacion procedente de los tenedores de juros y que, a nuestro entender, permite conocer mejor cuáles fueron las motivaciones de la inversión en juros, así como las repercusiones que los continuos valimientos, descuentos y anulaciones tuvieron sobre las economías domésticas de los juristas.

Para el estudio de los juristas hemos escogido la Iglesia, que se constituyó en el primer tenedor de juros del reino. La imposibilidad de abarcar toda la documentación eclesiástica y la falta de estadísticas generales que delimiten el papel de los juristas eclesiásticos nos lleva a acotar aún más nuestro estudio, tanto geográfica como cuantitativamente. Andalucía fue, por diversos motivos, riqueza agraria, desarrollo del comercio interior y cabecera del tráfico a Indias, región en que se desarrolló una intensa circulación monetaria, lo que la convierte en privilegiado observatorio para estudiar las repercusiones que tuvieron las emisiones de la deuda pública. Dentro de la Iglesia, se ha prestado una mayor atención al clero regular, tanto por su destacado papel como poseedor de juros como por cuestiones metodológicas, la conservación de sus archivos.

El presente estudio se encuadra en un proyecto más amplio que sobre la economía del clero regular andaluz iniciamos hace ya varios años ${ }^{3}$. Hipótesis básica en el mismo era el tratar de demostrar que la pretendida idea de pasividad y desidia de la Iglesia en la administración de sus propiedades, que de manera intencionada se habia ido gestando en el siglo XVIII y, posteriormente, había sido asumida por otros estudiosos hasta casi nuestros días, carecía del más mínimo respaldo documental y que, por el contrario, la gestión económica de la Iglesia no se diferenciaba, sustancialmente, de las actitudes más innovadoras de los estamentos laicos.

Nuestro objetivo en este estudio es analizar las causas del interés de la

2 Principalmente, Artola Gallego (1982), Castillo Pintado (1963 a y b), Domínguez Ortiz (1960), Toboso Sánchez (1987), Torres López y Pérez-Prendes (1967) y Ulloa (1977).

3 López Martinez, A. L. (1992). 
Iglesia hacia este tipo de inversión, la deuda pública 4 , y tratar de demostrar que aquél no respondió, exclusivamente, a criterios de seguridad en la inversión y comodidad a la hora de percibir una renta anual, sino que, además, obedeció a la búsqueda de una racionalización en la inversión, que trataba de conseguir mayores beneficios económicos.

\section{ADQUISICION DE JUROS POR LOS CONVENTOS}

Para estudiar la actitud de las comunidades eclesiásticas ante los juros contamos con varios tipos de documentos. En primer lugar, los libros de protocolos conventuales, que informan sobre su adquisición; en segundo lugar, diferentes relaciones de juristas que indican cuál fue el alcance de la participación de los eclesiásticos en esta modalidad de la deuda pública; finalmente, los libros de contabilidad monástica, que reflejan las fluctuaciones que experimentaron los abonos de los réditos de los juros.

Del análisis de algunos libros de protocolos conventuales ${ }^{5}$ se desprende que los primeros juros adquiridos por los conventos estudiados datan del siglo XV, figurando como primeros propietarios la Cartuja de las Cuevas, con tres juros con 35.000 maravedíes de rédito, dos recibidos por donación y uno por compra ${ }^{6}$, y el convento de monjas agustinas de $\mathrm{S}$. Leandro, que recibió la donación de un juro de $34.000 \mathrm{~ms}$. de rédito. No se puede, realmente, hablar de deuda pública al referirnos a estos primitivos juros, los juros «de merced", que consisten en el derecho, concedido por la Corona, a percibir una pensión anual 7. La mayoría de estos juros "de merced", vitalicios y perpetuos, recayeron en manos de las instituciones eclesiásticas ${ }^{8}$.

Durante la primera mitad del siglo XVI la documentación manejada confirma que los conventos continuaron beneficiándose de los juros perpe-

- El tema de la participación de la Iglesia en los juros ha sido tratado, entre otros, por Castillo Pintado (1963 a), pp. 758-759; Torres López y Pérez-Prendes (1967), p. 28, y Toboso Sánchez (1987), pp. 211-212.

5 Los protocolos estudiados corresponden a los conventos de Sta. Paula, S. Leandro, S. Clemente y Cartuja de Santa Maria de las Cuevas de Sevilla y carmelitas descalzas de Sanlúcar la Mayor.

- Muestra del interés de las instituciones eclesiásticas por las rentas públicas, aunque en este caso no se trata de un juro, es la compra por la Cartuja de 5/12 de las rentas de la Alcabala Vieja de la Carne de Sevilla entre 1448 y 1473 por 614.000 maravedies, Cuartero Huerta (1950), v. 1 , p. 211.

7 Toboso Sánchez (1987), p. 37.

8 Toboso Sánchez (1987), p. 32. 
tuos, algunos de ellos en especie, que la Corona les hacía merced, destacando en este sentido los donados a la Cartuja sevillana por D. Manuel I de Portugal (atunes y especias orientales) y por D. Carlos I de Castilla (atunes) 9 . Todavía, hasta 1560 , se puede afirmar que la mayor parte de los juros en circulación estaban en poder del clero ${ }^{10}$. Por el contrario, la participación del clero regular en la nueva modalidad de la deuda pública, los juros al quitar, no parece que tuviese importancia hasta las últimas décadas del siglo XVI.

A través de los libros de protocolos se observa cómo los conventos adquieren numerosos juros redimibles en las útimas décadas del siglo XVI mediante variados procedimientos, que comprenden herencias de religiosos, dotes de monjas, donaciones en retribución por servicios religiosos y compras. En total, los libros de protocolos estudiados registran la adquisición de 12 títulos de deuda pública, de los cuales 6 corresponden a títulos de juros, mientras que los otros 6 se trata de imposiciones de censos sobre juros de mayor cuantia, propiedad de particulares, modalidad que, a la vista de los datos, debió de ser bastante corriente. Hay que tener en cuenta que, en todo momento, los juros fueron considerados como un valor plenamente negociable, pudiendo ser objeto de cualquier tipo de operación comercial no sólo entre la Corona y un particular, sino tambien entre particulares. Podía ser objeto de compra-venta, de traspaso, utilizarse para pagar deudas o usarse como fianza en operaciones comerciales $y$, finalmente, ser utilizado como garantía en la constitución de un censo "1. Entre las adquisiciones hay registradas tres compras por un importe de 2.500 .000 maravedies.

Los réditos de los juros adquiridos durante el siglo XVI por las instituciones regulares eran superiores a los 600.000 maravedíes anuales de renta, estando el interes de estos juros comprendido entre los 14.000 y los 20.000 maravedies el millar, que es el predominante para la época, siendo la tipologia de los mismos muy amplia, ya que van desde los 5.357 hasta 319.090 maravedies de renta, el mayor de ellos.

Además de los protocolos monásticos, se cuenta para el siglo XVI con una serie de relaciones de titulares de distintas deudas públicas que permiten aproximarse a una evaluación de la participación de los conventos en dicho tipo de rentas. Para los años comprendidos entre 1586 y 1589 se dispone de cuatro relaciones de titulares de juros sobre alcabalas de Sevilla ${ }^{12}$. Entre las

9 Cuartero Huerta (1950), p. 405.

10 Castillo Pintado (1963 b), p. 259.

11 Toboso Sánchez (1987), p. 60.

12 Archivo Municipal de Sevilla (AMS), sección 1, Carpeta 173, n. 26, contiene las relaciones de 1586, 1587 y 1588; la de 1589 figura en la sección 3 , t. 2 , n. 4. 
mismas las diferencias son mínimas, por lo que hemos decidido analizar la de 1589. Los juros aparecen clasificados según tres categorias: perpetuos, al quitar y vitalicios. De éstos, los juros pertenecientes al clero regular eran los siguientes:

- 25 juros perpetuos cuya renta anual se eleva a $213.206 \mathrm{~ms}$., variando las rentas entre los 500 y 55.555 maravedies, aunque la mayoría se encuentra entre 4.000 y 12.000 maravedies, siendo la media de 8.528. Entre ellos hay tres cuyos réditos aparecen consignados en especie, 300 fanegas de trigo, aunque aparece su equivalencia en metálico. Los títulares de éstos eran 17 conventos, de los que 9 son de la ciudad, 3 son de otras localidades del Reino de Sevilla y 5 conventos son de fuera de Andalucía.

- 4 juros vitalicios con 28.000 maravedies de renta anual y pertenecen a 4 conventos de la ciudad. Tanto en los juros perpetuos como en los vitalicios el interés es reducido, probablemente debido a su antigüedad, al tratarse de juros medievales.

- 20 juros al quitar, cuya renta es de 1.165 .749 maravedies anyales y su renta media de 58.287 , oscilando las rentas entre 4.000 , para los más bajos, y 175.000 maravedies, los más altos. Los titulares son 16 conventos, de los que 8 son sevillanos y los restantes pertenecen a localidades de fuera de Andalucia, lo que da una idea de lo atractivo que resultaba la inversión en las alcabalas sevillanas, debido, sin duda, al rápido crecimiento de la ciudad.

En total, en esta relación figuran 49 títulos de juros en manos de instituciones monásticas, con unos réditos anuales de 1.406 .955 maravedíes. Aunque se trata de una sola de las numerosas rentas de la Corona sobre la que se situaban los juros, dada su importancia, permite realizar un muestreo de la inversión del clero regular andaluz en la deuda pública. Lo primero que salta a la vista es, a pesar del elevado volumen de la renta de los juros de los regulares, el escaso peso de éstos en el conjunto de los juros puestos en circulación ${ }^{13}$.

13 De un carácter similar al de los juros son los censos situados sobre las rentas municipales de la ciudad de Sevilla. Tambien se trata de deuda pública consolidada, si bien en este caso de carácter municipal y no estatal. Entre los compradores de la deuda municipal sevillana entre 1572 y 1596 figuran instituciones $e$ individuos eclesiásticos que adquieren $\mathbf{4 2 . 5 7 5 . 2 1 3 ~ m a r a v e d i e s , ~ l o ~}$ que supone sólo el $2,7 \%$ de la deuda municipal emitida, porcentaje muy bajo, parecido al estudiado en el caso de las alcabalas de la ciudad. Martínez Ruiz, J. I. (1992), pp. 349-371. 
— Total de juros impuestos sobre las alcabalas de Sevilla ...... 976

- Juros de regulares impuestos sobre ídem ................... 49

- Porcentaje de los segundos sobre los primeros ............... 5

- Importe del situado sobre alcabalas de Sevilla .. 155.301 .896 maravedíes

- Importe de los réditos de los juros de los regulares impuestos sobre ídem ............................... 1.406 .955 maravedies

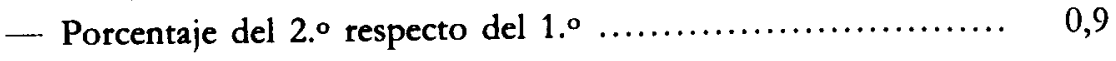

Como se ve, la participación de los conventos en la Deuda Pública es en el siglo XVI bastante reducida. Las causas son variadas; por una parte, la legislación civil, que prohibía la adquisición de juros redimibles por parte de eclesiásticos y extranjeros, que se mantuvo hasta ser abolida por Felipe II ${ }^{14}$. Pero tambien, por motivos económicos, en otro estudio hemos demostrado que en esta época se desarrolla una gran actividad de los conventos en la compra de tierras, que, además de ser tradicional en las economías monásticas andaluzas, desde la Edad Media ${ }^{15}$, resultaba, posiblemente, más atractiva, ya que el incremento de la demanda inelástica motivaría una subida de los precios de los artículos de primera necesidad que traería consigo la subida de la renta de la tierra. La generalización de la institución del mayorazgo a lo largo del siglo XVI limitó considerablemente el mercado de la tierra ${ }^{16}$, a lo que hay que añadir la aparición de otros competidores, la burguesía urbana ${ }^{17}$, lo que terminó encareciendo, apreciablemente, las propiedades rústicas, en un momento en que se comenzaban a apreciar los primeros síntomas del cambio de coyuntura, reflejados en el descenso de los precios de los productos agrarios ${ }^{18}$.

Durante el siglo XVII el interés de las órdenes religiosas por los juros se acentuó, como lo muestran las 24 adquisiciones que recogen los libros de protocolos para esta época. De estas adquisiciones 12 fueron por compra, también en 9 casos los conventos adquirieron tributos situados sobre juros de mayor cuantía. Las adquisiciones se realizaron con anterioridad a 1672, no registrándose ninguna adquisición con posterioridad. Los réditos de los juros y tributos situados sobre juros adquiridos suman 636.820 maravedíes anuales, lo que supone una media de 26.534 anuales, aunque el abanico resulta muy amplio, siendo el mayor de 374.000 maravedies de rédito anual. Los 12 títulos

14 Toboso Sánchez (1987), pp. 57-58.

15 Collantes de Terán (1979), pp. 137-138.

16 López Martínez, A. L. (1992), Pp. 176-178.

17 Bernal (1988), pp. 54-59.

18 Ponsot (1986), p. XXII. 
comprados en el siglo XVII importaron 23.000.000 de maravedies de nominal, que supone más de 10 veces la cantidad invertida por los conventos estudiados en este mismo tipo de operaciones durante el siglo anterior.

De todo lo anteriormente expuesto se desprende que la mayor parte de las adquisiciones, asi como el mayor volumen de inversión en deuda pública consolidada, se sitúa entre las últimas décadas del siglo XVI y la primera mitad del siglo XVII, en que los conventos adquirieron la mayor parte de sus títulos. Este interés de la Iglesia no decayó cuando comenzaron a producirse las primeras muestras del indudable agotamiento de las rentas públicas sobre las que se situaban los juros, lo que hizo que muchos títulos quedasen sin cabimiento al superar los situados el montante total de dicha renta; al mismo tiempo los monarcas comienzan a llevar a cabo los primeros descuentos de los réditos de dichos juros. Sin embargo, a partir de 1635 , fecha en que se puede decir que se institucionaliza el descuento de las medias annatas, todavía se registran 7 adquisiciones de juros, de las que 4 corresponden a compras por más de 11.000 .000 de maravedies, que supone casi la mitad de todo lo adquirido en compras de juros durante el siglo XVII. Por otra parte, si bien otras adquisiciones de juros tienen que ver con donaciones por servicios religiosos, dotes y herencias, no hay que ver en estas operaciones una actitud pasiva de las instituciones regulares, puesto que al tratarse en numerosas ocasiones de pagos por servicios religiosos concertados o por dotes de monjas al profesar, la comunidad tenía libertad para rechazar los títulos de juros y exigir otro tipo de bienes como medio de pago.

Es decir, que el interés de la Iglesia por los juros se prolongó algunas décadas más que el de los seglares. La Iglesia seguía adquiriendo juros cuando era público y notorio el descrédito de tales títulos. ¿Cuál pudo ser la causa de este prolongado interés de la Iglesia por los juros a pesar de su evidente deterioro? Sin duda alguna, fueron las reservas otorgadas por los monarcas, buena parte de las cuales recayeron sobre diversas instituciones eclesiásticas, que se convirtieron en entidades privilegiadas, parcial o totalmente, libres de los descuentos realizados sobre los réditos de los juros. En 1649 se institucionalizaron las reservas que los monarcas habian ido aplicando con anterioridad, resultando principalmente beneficiados los conventos de monjas y colegios de jesuitas. Así, al adquirir una de estas instituciones un juro, aunque estuviese depreciado, automáticamente pasaban a aplicársele los privilegios de que disfrutaban, lo que permitía la revalorización del mismo. Como dijimos anteriormente, la situación se prestaba a todo tipo de manipulaciones fraudulentas. Determinados propietarios de juros, dada la devaluación que éstos experimentaban, pudieron cederlos a la Iglesia, librándose de este modo de 
los descuentos, gracias a las reservas de que gozaban los juristas eclesiásticos, a cambio de percibir vitaliciamente las rentas de sus antiguos juros ${ }^{19}$. Tambien debió ser frecuente la compra, por las comunidades, de títulos devaluados por menor valor que el de su nominal, aunque no hemos podido contrastar este último aspecto documentalmente.

Una buena parte de las adquisiciones de juros por la Iglesia se efectuaron a particulares, lo que confirmaría lo que anteriormente hemos expuesto respecto a la transferencia de juros de particulares a la Iglesia. Toboso afirma que la Iglesia sólo adquirió de primera imposición algo más del $11 \%$ de los juros emitidos ${ }^{20}$; sin embargo, durante la segunda mitad del siglo XVIII diversos testimonios nos sitúan los réditos de los juros percibidos por los eclesiásticos en cerca de un $75 \%$ del total de los intereses devengados por los juros:

\begin{tabular}{lllll}
\hline & Eclesiásticos & \multicolumn{1}{c}{ Total } & $\%$ \\
\hline Corona de Castilla 1750 & $\ldots \ldots \ldots \ldots \ldots . \ldots$ & 9.998 .082 & 13.335 .960 & 74,9721 \\
Reino de Sevilla $1773 \ldots \ldots \ldots \ldots \ldots$. & 1.000 .000 & 1.339 .000 & 74,6822 \\
\hline
\end{tabular}

En este sentido, hay que destacar que de los 8 juros que pertenecian al colegio jesuita de S. Hermenegildo de Sevilla en 1645, sólo 3 están encabezados en dicho colegio ${ }^{23}$, mientras que ninguno de los 11 juros que poseía el convento de S. Francisco de Sevilla estaba encabezado en él, según unas relaciones de 1764-81 24 .

Durante la segunda mitad del siglo Xvil el papel de la Iglesia como propietaria de juros subió considerablemente, al mismo tiempo que bajaba el de otros sectores sociales, que ante la caída de los réditos de los juros trataron de desprenderse de ellos, o bien vieron cómo los perdian al quedar sin cabimiento. Una prueba de la mayor participación de la Iglesia en la deuda

19 Toboso Sánchez (1987), pp. 211-212.

20 Dominguez Ortiz (1960), p. 325; Torres López y Pérez-Prendes (1967), p. 30; Herrera Garcia (1988), p. 97 y Toboso Sánchez (1987), p. 182.

21 Grupo'75 (1977), p. 201.

22 Relación de juristas del Reino de Sevilla elaborada por Herrera Garcia (1988), pp. 104-117, en base a una certificación del contador D. Antonio de Domezaín.

${ }_{23}$ AMS, Papeles del Conde del Aguila, folio, t. 12, 1-2.

24 Archivo Provincia Bética Franciscana (APBF), carpeta 43, leg. 45. 
pública lo tenemos en las nuevas adquisiciones de deuda pública consolidada municipal para los años comprendidos entre 1665 y 1736 25:

Deuda municipal vendida 11.333 .393 rs.

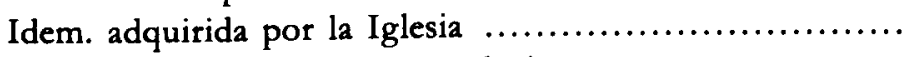
Porcentaje de la $2 .^{2}$ respecto a la $1 .^{2}$ 60,21

El predominio de la Iglesia en estas adquisiciones de deuda municipal contrasta con las relaciones del siglo XVI en que la proporción encontrada era mínima. Tambien llama la atención el elevado volumen de deuda municipal adquirida por la Iglesia, que es 6 veces mayor que la invertida en la relación del siglo XVI. Hay que suponer que al cesar la adquisición de juros a mediados del siglo XVII, los eclesiásticos fijaron su atención en la adquisición de deuda pública del Ayuntamiento sevillano.

Por último, durante el siglo XVIII, si bien no se produjeron nuevas adquisiciones de juros, debido al acaparamiento de los mismos durante el siglo anterior, la Iglesia, según las diversas relaciones de la época, aparece convertida en la principal acaparadora de juros, beneficiándose con los $3 / 4$ de los réditos de los juros en la Corona de Castilla. Sin embargo, como a continuación veremos, se trataba de títulos muy devaluados, cuya incidencia en la economía conventual es mínima, menos de un $5 \%$ de todos sus ingresos en la corona de Castilla ${ }^{26}$.

\section{INCIDENCIAS DE LOS DESCUENTOS EN LOS JUROS DE ECLESIASTICOS}

Aunque la mayor parte de las instituciones eclesiásticas se vieron beneficiadas con las reservas concedidas por la Corona, que las excluian de los descuentos y valimientos, sin embargo, la ruina de la Hacienda Real y las sucesivas operaciones de saneamiento de la misma, entre las que las más importantes eran la extinción de los juros, lógicamente, terminaron afectando a los juros de los eclesiásticos, que sufrieron una brusca caída de sus réditos desde comienzos del siglo XVIII como consecuencia de la Guerra de Sucesión y del caos hacendístico subsiguiente. Muchos de los cuales quedaron anulados y el resto terminaron siendo afectados por los mismos descuentos que se aplicaron a los de los restantes juristas.

25 Martinez Ruiz, J. I. (1992), pp. 373-380.

26 Grupo'75 (1977), p. 201. 
Al principio, los valimientos de los réditos de los juros se hicieron de forma provisional, como muestran las restituciones que en forma de nuevos juros, por importe de los réditos de que se había valido la Corona, se llevaron a cabo ${ }^{27}$. En este sentido, tenemos el caso de los juros propiedad de los colegios jesuitas andaluces a mediados del siglo XVII. Para ello nos hemos basado en un borrador de cuentas realizado para calcular las cantidades de que se había valido S.M. de los réditos de los colegios de los jesuitas andaluces durante algunos años a mediados del siglo XVII ${ }^{28}$. En los años 1639, 1640,1643, 1644, 1645 y 1646, la Corona se valió de las medias annatas de la totalidad de los juros situados sobre la Hacienda Pública; para los años 1641 y 1642 no se aplicó el descuento de las medias annatas. Si bien los juros propiedad de los jesuitas se vieron afectados por tal medida, se beneficiaron de ciertas compensaciones, lo que les dio una posición de privilegio respecto al resto de los juristas. En primer lugar, se beneficiaron de ciertas exenciones en el descuento de la media annata, de modo que en lugar de descontarles la mitad de los réditos de los juros, hemos calculado que el monarca sólo se valió del $22 \%$ de los réditos de los colegios jesuitas andaluces para estos 6 años, aunque en proporciones variables para cada colegio y cada año, ya que en algunas ocasiones alguno de los colegios se vio obligado a vender la totalidad o parte de la carta de pago de sus juros y en este caso no se benefició de la exención.

En segundo lugar, los colegios jesuitas se vieron compensados de estos descuentos en los réditos de sus juros con la entrega de otros nuevos por valor equivalente a las cantidades de que se había valido S.M. Los descuentos de 1639,1640 y 1643 fueron compensados por juros de un nominal equivalente a los descuentos y unos réditos de 416.874 maravedies situados sobre las Salinas de Andalucía Tierra Adentro, para ser abonados desde principios de 1645. Mientras que los valimientos correspondientes a los años 1644,1645 y 1646 lo fueron con juros de 395.087 maravedíes de renta sobre el primer $1 \%$ de Sevilla en tercera situación, pagaderos a partir de 1647.

Pero la situación de los juros eclesiásticos terminó viêndose abocada a la misma crisis experimentada por los restantes juros, especialmente desde las primeras décadas del siglo XVIII. La mejor muestra de este deterioro la encontramos reflejada en la relación de las propiedades eclesiásticas del

27 Artola Gallego (1982), p. 152.

28 Archivo Histórico Nacional (AHN), sección clero, jesuitas, carpeta 134, legajo 3. Es una relación de los juros que poseian los colegios jesuitas de la provincia de Andalucía elaborada con el fin de obtener compensaciones por los descuentos que habian sufrido y de la que, por la reserva que disfrutaban, estaban excluidos. 
Arzobispado sevillano elaborada en $1715^{29}$. De los 271 juros que se mencionan en dicha relación, a los que corresponden 15.933 .216 maravedies de rédito, propiedad de 44 conventos, 211 juros, casi el $80 \%$ de los mismos aparecen sin cabimiento, sin percibir nada de sus réditos. En cuanto a los réditos que se cobraban, sólo se perciben 2.138 .226 maravedies, que significaban el $13,42 \%$ de los réditos nominales de dichos juros. Algunos conventos vieron cómo los ingresos de sus juros desaparecian totalmente, mientras que otros que basaban sus ingresos en los réditos de sus juros, su caída llevó a estas comunidades a situaciones auténticamente dramáticas, dando lugar, junto a la caida de los intereses de los censos que poseían, a una de las mayores crisis conocida por los conventos andaluces ${ }^{30}$. Esta situación queda reflejada en las visitas de los vicarios y visitadores a los conventos de monjas, en que a la vista del grave deterioro de la economía monástica imponen drásticas reducciones en los gastos de la comunidad y nuevas orientaciones en la administración de sus propiedades ${ }^{31}$.

\section{EVOLUCION COMPARADA DE LOS INGRESOS PROCURADOS POR LOS JUROS RESPECTO A LOS INGRESOS PROCURADOS POR OTRAS FUENTES}

Los libros de contabilidad monásticos permiten conocer cuál fue la evolución real de los juros de su propiedad. Los libros de cuentas del monasterio de monjas cistercienses de S. Clemente en Sevilla abarcan desde 1623 hasta $1823^{32}$, período que comprende los momentos decisivos de la historia de los juros. El citado monasterio llegó a contar entre sus bienes con 13 títulos de juros y un tributo impuesto sobre un juro. Habia 6 juros sobre alcabalas de Sevilla, 3 sobre el Almojarifazgo mayor de Sevilla, 1 sobre el

29 Archivo Catedral de Sevilla (ACS), Mesa Capitular, 1.116, corresponde a una relación de las propiedades de las instituciones eclesiásticas del arzobispado de Sevilla para la distribución del subsidio.

30 Aguilar Piñal (1982), p. 293, recoge el caso de las monjas agustinas del convento de la Encarnación de Sevilla, que el 29 de septiembre de 1710, a las cinco de la mañana, abandonaron el convento y se dirigieron procesionalmente a la catedral para implorar el socorro del cabildo. Según la relación de 1715, sus ingresos por réditos de juros ascendian a 42.676 reales anuales, pero sólo percibian 91 reales por este concepto, al estar sin cabimiento todos los juros menos uno, por lo que únicamente les quedaba la renta de las otras posesiones, que ascendian a 2.750 reales anuales para alimentar a la comunidad de monjas.

31 López Martinez, Antonio Luis (1992), pp. 284-285.

32 En el Archivo del Monasterio de S. Clemente existen 54 libros de cuentas con numeración propia, del 1 al 38, estando el resto sin numerar, que abarcan dicho periodo. 
Almojarifazgo de Indias y otro, éste en especie, sobre las Salinas de Andalucía. Aunque en ningún momento llegaron a estar todos los tributos al corriente, sus réditos montaban $\mathbf{4 4 8 . 4 4 7}$ maravedies y 120 arrobas de sal.

Hasta 1635 los libros no registran ningún tipo de pérdidas en el cobro de los juros, lo que da a entender que los réditos eran cobrados de forma regular sin que se viesen afectados por descuentos o valimientos en sus réditos. Entre 1635 y 1701 el capítulo de gastos registra una partida de pérdidas en el cobro de juros, es decir, en los ingresos se recoge el rédito teórico de cada juro. y en los gastos, las pérdidas ocasionadas por venta de cartas de pago, descuentos

\section{CUADRO 1}

Evolución de los ingresos por juros del Monasterio de S. Clemente de Sevilla (1623-1823)

(medias anuales por decenio)

\begin{tabular}{|c|c|c|}
\hline Fecba & Réditos & Indice \\
\hline $1623-29 \ldots \ldots \ldots$ & 200.592 & 118,90 \\
\hline 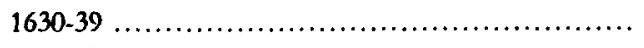 & 284.326 & 168,53 \\
\hline 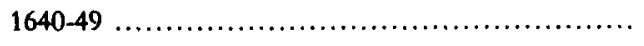 & 235.130 & 139,37 \\
\hline 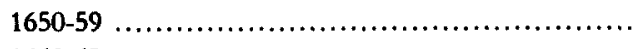 & 252.797 & 149,84 \\
\hline 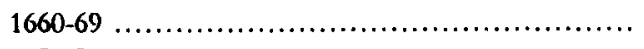 & 394.055 & 233,57 \\
\hline 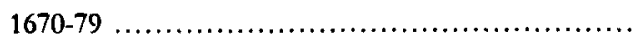 & 331.148 & 196,29 \\
\hline 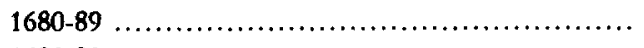 & 319.863 & 189,60 \\
\hline 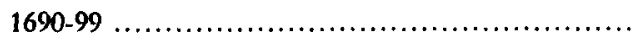 & 291.944 & 173,05 \\
\hline 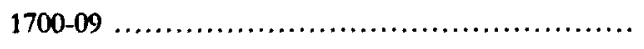 & 76.448 & 45,31 \\
\hline 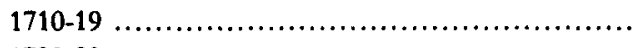 & 29.179 & 17,30 \\
\hline 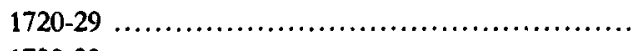 & 69.109 & 40,96 \\
\hline 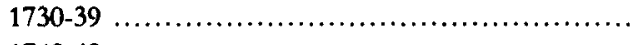 & 124.230 & 73,64 \\
\hline 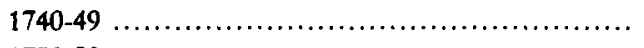 & 87.245 & 51,71 \\
\hline 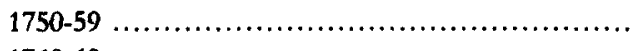 & 99.813 & 59,16 \\
\hline 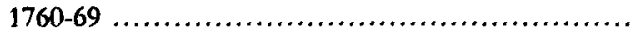 & 112.516 & 66,69 \\
\hline 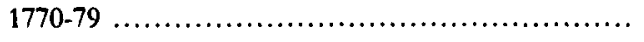 & 154.456 & 91,55 \\
\hline 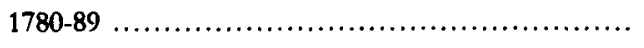 & 156.629 & 92,84 \\
\hline 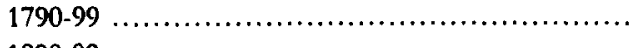 & 157.476 & 93,34 \\
\hline 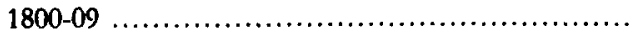 & 62.783 & 37,21 \\
\hline 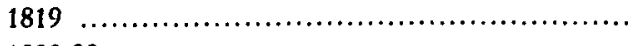 & 47.818 & 28,34 \\
\hline 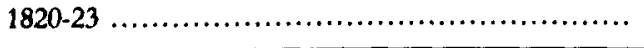 & 55.294 & 32,78 \\
\hline
\end{tabular}

Datos: reales de vellón Base $(1623-1823)=100$.

FUENTES: Libros de contabilidad del Monasterio de S. Clemente 
aplicados por el monarca a los réditos de los juros, atrasos en la percepción de los réditos, etc. En estos casos, el cálculo de la anualidad correspondiente a cada juro se ha hecho restando a lo que corresponde a los réditos teóricos las perdidas consignadas para tal período. A partir de 1701 ya no se consignan las pérdidas, sino que en cada juro se consigna lo que ingresó realmente por dicho concepto.

El número de juros propiedad del monasterio experimentó una evolución durante el período estudiado. En 1623 el convento poseía 7 títulos de juro y la fluctuación de sus réditos se debió, por una parte, a la adquisición de nuevos juros $y$, por otra parte, a la falta de cabimiento provisional que tuvieron varios juros del monasterio. Durante la mayor parte del siglo esta falta de cabimiento fue transitoria, ya que al cabo de algunos años se volvian a percibir los réditos correspondientes a dichos juros. Desde 1623 a 1647 el número de juros creció hasta 12 al adquirirse nuevos juros y no quedar ninguno sin cabimiento. Desde 1666 el número de juros comenzó a disminuir por falta de pago de algunos de ellos. Durante el siglo XviIl el número de los juros corrientes se llegó a reducir hasta sólo 2, oscilando durante todo el siglo dicho número entre 2 y 5 , quedando fijado en 5 el número de juros corrientes desde 1769. Finalmente, durante el siglo XIX el número de juros corrientes volvió a sufrir numerosas irregularidades, llegando incluso a no cobrarse ninguno durante algunos años.

La evolución seguida por los réditos de juros percibidos por el convento de $\mathrm{S}$. Clemente queda recogida en el cuadro 1.

La comparación de esta serie con la de los ingresos totales del monasterio permitirá, por una parte, conocer el peso específico de los réditos de los juros en la economia monástica y, en segundo lugar, comprobar si en relación con las restantes partidas de ingresos la inversión en juros fue o no rentable.

Período

Porcentaje de los juros sobre los ingresos del monasterio

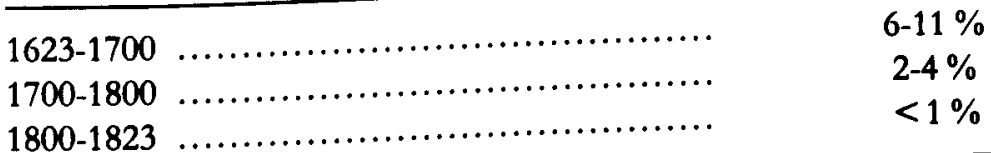

En el primer caso, los réditos de los juros nunca tuvieron una participación destacada en la economía del Monasterio de S. Clemente, que, fundado en las décadas siguientes a la conquista de la ciudad a expensas del rey, fue 
dotado con un importante patrimonio rústico, cerca de las 3.000 has., y con numerosas casas y solares de la ciudad, todo lo cual constituía la base de sus ingresos. Los réditos de los juros fueron perdiendo importancia conforme los descuentos y la falta de cabimiento iba deteriorándolos, al mismo tiempo que las rentas de los inmuebles se revalorizaban.

El mejor sistema para comprobar si la inversión en juros fue más rentable que otras partidas del convento estriba en la utilización de una técnica estadística eficaz. Nos ha parecido como más adecuada la tendencia lineal; sin embargo, dada la longitud de la serie, 200 años, en la que se han sucedido diversas vicisitudes en las series es necesario fragmentarlas para calcular las diferentes fluctuaciones atravesadas. El cuadro 2 ofrece la tendencia central de la serie en sucesivos períodos.

\section{CUADRO 2}

Comparación de las series de ingresos por juros e ingresos totales del Monasterio de S. Clemente de Sevilla (1623-1823)

(tendencias lineales de los números índices. Base 1623-1823=100)

\begin{tabular}{|c|c|c|}
\hline Periodo & Concepto & Erwación de la tendencia \\
\hline $1623-1649 \ldots$ & $\begin{array}{l}\text { Ingresos juros } \\
\text { Ingresos totales }\end{array}$ & $\begin{array}{l}Y=127,559+0,953 X \\
Y=107,865+0,328 X\end{array}$ \\
\hline 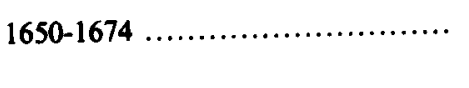 & $\begin{array}{l}\text { Ingresos juros } \\
\text { Ingresos totales }\end{array}$ & $\begin{array}{l}Y=146,822+3,661 X \\
Y=107,579-0,876 X\end{array}$ \\
\hline $1675-1699 \ldots$ & $\begin{array}{l}\text { Ingresos juros } \\
\text { Ingresos totales }\end{array}$ & $\begin{array}{l}Y=195,343-1,118 X \\
Y=95,336-1,784 X\end{array}$ \\
\hline $1700-1724 \ldots \ldots \ldots \ldots \ldots$ & $\begin{array}{l}\text { Ingresos juros } \\
\text { Ingresos totales }\end{array}$ & $\begin{array}{l}Y=51,260-1,721 X \\
Y=62,672-0,749 X\end{array}$ \\
\hline $1725-1749 \ldots$ & $\begin{array}{l}\text { Ingresos juros } \\
\text { Ingresos totales }\end{array}$ & $\begin{array}{l}Y=64,911-0,373 X \\
Y=87,490+0,030 X\end{array}$ \\
\hline $1750-1774 \ldots \ldots \ldots \ldots$ & $\begin{array}{l}\text { Ingresos juros } \\
\text { Ingresos totales }\end{array}$ & $\begin{array}{l}Y=51.468+1,476 X \\
Y=93,012+0,233 X\end{array}$ \\
\hline $1775-1799 \ldots$ & $\begin{array}{l}\text { Ingresos juros } \\
\text { Ingresos totales }\end{array}$ & $\begin{array}{l}Y=92,005+0,042 X \\
Y=87,672+2,802 X\end{array}$ \\
\hline $1800-1823 \ldots \ldots$ & $\begin{array}{l}\text { Ingresos juros } \\
\text { Ingresos totales }\end{array}$ & $\begin{array}{l}Y=41,307-1,693 X \\
Y=165,766-0,683 X\end{array}$ \\
\hline
\end{tabular}

El siglo XVII fue el período durante el cual los juros eclesiásticos produjeron una mayor rentabilidad, especialmente en la segunda mitad. El crecimiento experimentado por los ingresos procedentes de los juros del 
Monasterio de S. Clemente entre $1650-1674$ superaron ampliamente el crecimiento de los ingresos de las restantes partidas, que, a su vez, acusan una tendencia decreciente. En el incremento de los ingresos por juros se apuntan, de una parte, la adquisición de nuevos juros por el monasterio favorecida por las circunstancias que señalábamos con anterioridad; de otra, por las ventajas derivadas de sus posición privilegiada al quedar excluida, desde 1649 , de los descuentos aplicados a los réditos de los juros. La tendencia decreciente de las restantes partidas de ingresos del monasterio se explica por la caida de la renta de la tierra ${ }^{33}$, así como de la renta urbana ${ }^{34}$. Posteriormente, cuando en las últimas décadas del siglo los ingresos de los juros también tienden a descender, la caída será bastante menos pronunciada que la de los ingresos derivados de las restantes partidas.

A partir de 1700 las circunstancias cambian, la Guerra de Sucesión dificulta el abono de los intereses de los juros, incluso en el caso de los juristas privilegiados. Muchos de los juros quedan sin cabimiento y en los corrientes se atrasan los pagos y los descuentos comienzan a afectar a los juros reservados. Durante la primera mitad del siglo asistimos a los intentos por parte de la Real Hacienda de liberarse de la hipoteca de los juros, pero la dificultad de disponer de numerario para la amortización llevan a las autoridades hacendísticas a buscar otros procedimientos más drásticos basados en la anulación de los títulos de los juros y, con ello, de sus intereses. Todo ello dio lugar a que los ingresos de los juros descendiesen y su cobro fuese bastante más irregular. Por contra, los ingresos generales del monasterio tendieron en este periodo a estabilizarse, lo que da lugar a un comportamiento divergente de ambaś partidas.

Durante la segunda mitad del siglo XVIII se produce una mejoría en la situación de los juros gracias a las operaciones de saneamiento de las autoridades hacendísticas castellanas, se normaliza el abono de los intereses de los juros, llegándose, incluso, a pagar algunos que habian quedado sin cabimiento en periodos anteriores. Todo lo cual permite una notable subida de los ingresos por este concepto, si bien no vuelven a alcanzar los niveles existentes a mediados del siglo anterior. A su vez, los ingresos totales del monasterio experimentan una fuerte subida, especialmente durante el último cuarto del siglo, lo que evidencia, aún más, los divergentes comportamientos de las dos series estudiadas. Los datos que poseemos de 11 juros que pertenecian al Convento de S. Francisco de Sevilla ofrecen esta misma imagen

33 Ponsot (1986), p. XXV.

34 López Martinez, A. L. (1992), p. 326. 
de regularidad en su percepción. Entre 1764 y 1781 la diferencia entre los años en que se pagan más réditos y los que menos son de sólo un $7 \% 35$.

Finalmente, en las primeras décadas del siglo XIX se produce la definitiva desaparición del patrimonio económico de la Iglesia. Tambien aquí las diferencias entre los juros y las restantes partidas de ingresos fueron notables. Los juros sufrieron duramente los efectos de la guerra, dejándose de percibir desde 1810 hasta 1819; finalmente, a partir de 1823, dejan de consignarse partidas de juros en las cuentas del monasterio. Por su parte, la comunidad siguió percibiendo las rentas procedentes del resto de sus propiedades con toda normalidad hasta el momento mismo de su expropiación por el gobierno liberal.

\section{CONCLUSION}

El papel inmovilista que tradicionalmente se le ha venido atribuyendo a la Iglesia española en la gestión de su patrimonio dista mucho de ser realidad. Por el contrario, los eclesiásticos supieron dotar a la administración de sus bienes de una cierta flexibilidad que les permitía adecuarse con facilidad a las diversas fluctuaciones de la coyuntura económica. Para ello contaron con un importante y rico patrimonio, en el que la diversificación era una de las notas dominantes. En segundo lugar, utilizaron el recurso a la condición de privilegiados cuando se trató de conseguir mayores ventajas de sus bienes; finalmente, las exacciones de carácter extraeconómico, limosnas, donativos, mandas testamentarias... a que sometieron a buena parte de la sociedad de la época les permitió disponer de un flujo constante de capital del que hacer uso cuando la ocasión se tornara favorable y empujaba a la compra de determinados bienes que por diferentes circunstancias salían al mercado.

Una vez que el mercado inmobiliario rústico comenzó a cerrarse como consecuencia de la generalización de la institución del mayorazgo y cuando las elevadas inversiones que requerían se volvieron menos rentables como consecuencia del decremento de la demanda inelástica, la Iglesia vio en la inversión en valores mobiliarios una salida al capital que la mentalidad de la época iba transfiriendo del sector laico hacia las arcas eclesiásticas. El crédito ya había sido utilizado con anterioridad por la Iglesia con diferentes fines, pero ahora aparece como la opción más rentable. El censo consignativo y los juros al quitar fueron mecanismos que la Iglesia utilizará para invertir sus

35 APBF, carp. 43, leg. 45. 
bienes, pero lejos de buscar sólo una inversión segura y que proporcionase un abono comodo y regular, la Iglesia buscó en esta inversión una rentabilidad que otros sectores no le ofrecian. Por una parte, la elevada rentabilidad de estos títulos, superior al $5 \%$ en el siglo XVI y del $5 \%$ despues de $1621 \mathrm{y}$, por otra parte, la posición de privilegio conferida a determinadas instituciones eclesiásticas por la Corona a la hora de aplicarles descuentos y valimientos a los réditos de los juros, hicieron que la Iglesia con la adquisición de juros intentase efectuar la mejor inversión que dadas las circunstancias se le ofrecía para su dinero. $\mathrm{Si}$, a medio plazo, la situación se tornó desfavorable habrá que atribuirlo a un error de cálculo de los eclesiásticos y no a una desidia en la gestión de sus bienes.

\section{BIBLIOGRAFIA}

Agullar Piñal, F. (1982): Historia de Sevilla. El siglo XVIII, Sevilla, Publicaciones de la Universidad de Sevilla.

Artola Gallego, M. (1982): La Hacienda del Antigwo Régimen, Madrid, Alianza Editorial / Banco de España.

ATIENZA LóPEZ, A. (1991): "Transformaciones en el sistema de crédito y crisis de las economías monásticas en Aragón a fines del Antiguo Régimen", Revista de Historia Económica, 3 (1991), pp. 499-512.

Bennassar, Bartolomé (1974): «Consommation, investissements, mouvements de capitaux en Castille aux XVI ${ }^{c}$ et XVII sièclesn, en Hommage a Ernest Labrousse, París, Pp. 139-155.

Bernal, A. M. (1988): Economia e bistoria de los latifundios, Madrid, Instituto de España, Espasa-Calpe.

CANGA-ARgÚElles, José (1826-1827): Diccionario de Hacienda, vocablo "Juros».

CARANDE Y Thovar, R. (1967): Carlos $V$ y sus banqueros, Madrid, Sociedad de Estudios y Publicaciones, 3 volúmenes.

Castillo Pintado, A. (1963a): «Dette flottante et dette consolidée en Espagne de 1577 a $1600 \%$, Annales, E.S.C., pp. 745-759.

(1963b): «Los juros de Castilla, apogeo y fin de un instrumento de créditom, Hispania, n. LXXXIX, pp. 43-70.

COllaNTES DE TERÁN SÁNCHEZ, A., (1979): “Génesis de la gran propiedad en la Baja Edad Media; 12 propiedad eclesiástica sevillanam, en La economia agraria en la Historia de España, Madrid, Alfaguara, pp. 133-140.

CuArtero HuerTA, B. (1950): Historia de la Cartuja de Sta. M. de las Cuevas de Sevilla y de su filial de Cazalla de la Sierra, 2 vols., Madrid, Real Academia de la Historia.

Domínguez ORTIZ, A. (1960): Politica y Hacienda de Felipe IV, Madrid.

(1974): Orto y ocaso de Sevilla, 2 edc., Sevilla, Publicaciones de la Universidad de Sevilla.

(1984): Historia de Sevilla. La Sevilla del siglo XVII, Sevilla, Publicaciones de la Universidad de Sevilla. 
GRUPO'75 (1977): La economia del Antiguo Régimen. La "Renta Nacional» de la Corona de Castilla, Madrid, Universidad Aútonoma.

Herrera GarcíA, A. (1988): «Los “juristas” eclesiásticos en la Sevilla de 1773», Archivo Hispalense, n. 217, pp. 95-118.

LÓPEZ MARTINEZ, A. L. (1992): La economia de las órdenes religiosas en el Antiguo Régimen. Sus propiedades y rentas en el Reino de Sevilla, Sevilla, Diputación Provincial.

MARTínez Ruiz, J. I. (1992): Finanqas municipales y crédito público en la España Moderna. La Hacienda de la ciudad de Sevilla, 1528-1768, Sevilla, Ayuntamiento de Sevilla.

Ponsot, P. (1986): Atlas de Historia económica de la Baja Andalucia (siglos XVI-XIX), Granada, Editoriales Andaluzas Unidas.

Ruiz MARTíN, Felipe (1975): "Crédito y banca, comercio y transportes en la etapa del capitalismo mercantil», en Actas Primeras Jornadas de Metodologia aplicada a las Ciencias Históricas, Santiago de Compostela, pp. 725-749.

Toboso SÁnchez, P. (1987): La deuda pública castellana durante el Antiguo Régimen (juros), Madrid, Instituto de Estudios Fiscales.

Torres Lopez, M., y Perez-Prendes y Muñoz de ARraCo, J. M. (1967): Los juros. (Aportación documental para una bistoria de la deuda pública en España), Madrid, Instituto de Estudios Fiscales.

UlloA, M. (1977): La Hacienda Real de Castilla en el reinado de Felipe II, Madrid. 